\title{
Comparison of CKD-EPI Cystatin C and Creatinine Glomerular Filtration Rate Estimation Equations in Asian Indians
}

\author{
Boon Wee Teo, ${ }^{1}$ Charumathi Sabanayagam, ${ }^{2,3,4}$ Jiemin Liao, ${ }^{3}$ Qi Chun Toh, ${ }^{1}$ Sharon Saw, ${ }^{5}$ \\ Tien Yin Wong, ${ }^{2,3,6}$ and Sunil Sethi ${ }^{7}$ \\ ${ }^{1}$ Department of Medicine, Yong Loo Lin School of Medicine, National University of Singapore and National University Health System, \\ $1 E$ Kent Ridge Road, Level 10 NUHS Tower Block, Singapore 119228 \\ ${ }^{2}$ Singapore Eye Research Institute, c/o Singapore National Eye Center, 11 Third Hospital Avenue, Singapore 168751 \\ ${ }^{3}$ Department of Ophthalmology, Yong Loo Lin School of Medicine, National University of Singapore and National University Health \\ System, 1E Kent Ridge Road, NUHS Tower Block, Singapore 119228 \\ ${ }^{4}$ Office of Clinical Sciences, Duke-NUS Graduate Medical School, National University of Singapore, 8 College Road, Singapore 169857 \\ ${ }^{5}$ Department of Laboratory Medicine, National University Hospital and National University Health System, \\ 5 Lower Kent Ridge Road, Singapore 119074 \\ ${ }^{6}$ Ophthalmology and Visual Sciences Academic Clinical Program, Duke-NUS Graduate Medical School, \\ National University of Singapore, 8 College Road, Singapore 169857 \\ ${ }^{7}$ Department of Pathology, Yong Loo Lin School of Medicine, National University of Singapore and National University Health System, \\ $1 E$ Kent Ridge Road, Level 10 NUHS Tower Block, Singapore 119228
}

Correspondence should be addressed to Boon Wee Teo; mdctbw@nus.edu.sg

Received 14 January 2014; Accepted 11 March 2014; Published 27 April 2014

Academic Editor: Jaime Uribarri

Copyright (C) 2014 Boon Wee Teo et al. This is an open access article distributed under the Creative Commons Attribution License, which permits unrestricted use, distribution, and reproduction in any medium, provided the original work is properly cited.

Background. Chronic kidney disease (CKD) is identified in the general population using estimated glomerular filtration rates (eGFR) calculated from a serum creatinine-based equation, the chronic kidney disease-epidemiology collaboration (CKD-EPI) equation. Using serum cystatin $\mathrm{C}$ in combination may improve eGFR accuracy. We evaluated the new CKD-EPI equations incorporating cystatin $\mathrm{C}$ in a population of Asian Indians in classifying CKD across body mass index, diabetes, and hypertension status.Methods. We retrieved standardized serum creatinine and serum cystatin C data from a cohort of 2877 Asian Indians aged 40-80 years from the Singapore Indian Eye Study and calculated eGFR (in $\mathrm{mL} / \mathrm{min} / 1.73 \mathrm{~m}^{2}$ ) with the new CKD-EPI equations and serum creatinine only equation.Results. The creatinine only equation mean eGFR $(88 \pm 17)$ was similar to using spline Log cystatin C $(88 \pm 22)$. The lowest mean eGFR $(81 \pm 21)$ was obtained with the spline Log cystatin C-age, sex, and weight equation. The creatinine only equation had the fewest participants (7.1\%) with eGFR $<60$ and spline Log cystatin C-age, sex, and weight equation had the most (16.1\%).Conclusions. Using serum cystatin C resulted in widely varying eGFR which significantly affected the classification of chronic kidney disease.

\section{Introduction}

Chronic kidney disease is identified in the general population using estimated glomerular filtration rates (eGFR) calculated from formulae [1]. Serum creatinine-based equations, such as the Modification of Diet in Renal Disease study equation [2] and the Chronic Kidney Disease-Epidemiology Collaboration (CKD-EPI) equation [3], are commonly used for clinical care and research. However, serum creatinine levels are affected by non-GFR factors such as muscle mass (body composition), diet, and medications [4]. It has been shown that, using another filtration marker, such as serum cystatin $\mathrm{C}$, in combination with serum creatinine in prediction equations, the accuracy of GFR estimation is improved [5-7]. GFR estimation using serum cystatin C may be affected differently by obesity (body fat distribution). The CKD-EPI group recently published the combination of serum creatinine and cystatin $\mathrm{C}$ equations and other 
serum cystatin C-based equations which incorporated other variables such as weight or diabetes [8]. In this study we assess GFR estimation using these equations in an ethnic AsianIndian population and examine their performance in relation to body mass index, diabetes, and hypertension.

\section{Methods}

2.1. Study Population. The present study utilized data from the Singapore Indian Eye Study (SINDI), a population-based cross-sectional study of 3,400 Indians aged 40-80 years, conducted from 2007 to 2009 with detailed methodology reported elsewhere [9]. In brief, from a computer-generated random list of 11,616 Indian names provided by the Ministry of Home Affairs, 6,350 adults were selected by an agestratified random sampling method. Of the 4,497 eligible participants, 3,400 participated in the study with a response rate of $75.6 \%$. For this analysis, we included those with data on serum creatinine and serum cystatin $\mathrm{C}$ measurements $(n=2877)$.

2.2. Laboratory Assays. We retrieved stored serum and urine samples for assays performed in a central clinical laboratory. The assays were traceable to standardized reference materials using manufacturer provided calibrators where applicable. Creatinine concentrations were determined by the Jaffe method on the Beckman DxC800 analyzer, with manufacturer provided calibrators traceable to SRM 967. The concentration of serum cystatin $C$ was measured using particle-enhanced immunoturbidimetric assay calibrated with materials traceable to ERM-DA471/IFCC, and urine albumin was assayed with a PEG-enhanced immunoturbidimetric method on the Siemens ADVIA 2400 platform (http://www.siemens.com).

2.3. Measurement of Covariates. Age was defined as the age at the time of examination and was categorized into 2 groups: 40-65 and $>65$ years. Body mass index (BMI) was calculated as weight in kilograms divided by the square of height in meters $\left(\mathrm{kg} / \mathrm{m}^{2}\right)$. BMI was categorized into <20, 20-25, 25-30 (overweight), and $\geq 30 \mathrm{~kg} / \mathrm{m}^{2}$ (obese). Diabetes mellitus was defined as a casual plasma glucose $\geq 200 \mathrm{mg} / \mathrm{dL}(11.1 \mathrm{mmol} / \mathrm{L})$ or self-reported physician-diagnosed diabetes or use of glucose-lowering medication. Hypertension was defined as systolic BP $\geq 140 \mathrm{~mm} \mathrm{Hg}$ or diastolic BP $\geq 90 \mathrm{~mm} \mathrm{Hg}$ or selfreported previously diagnosed hypertension.

2.4. Statistics. We estimated GFR (eGFR) using the CKDEPI equations, where Scr is serum creatinine and Scys is serum cystatin $\mathrm{C}$, and all the study participants were treated as "white" $[3,8]$.

(1) Serum Creatinine 2009 Equation (Age, Sex, and Race) [3]. Consider $141 \times \min (\mathrm{Scr} / \kappa, 1)^{\alpha} \times \max (\mathrm{Scr} / \kappa, 1)^{-1.209} \times$ $0.993^{\text {Age }}[\times 1.018$ if female] $[\times 1.159$ if black], where $\kappa$ is 0.7 for females and 0.9 for males, $\alpha$ is -0.329 for females and -0.411 for males, $\min$ is the minimum of $S c r / \kappa$ or 1 , and $\max$ is the maximum of $\mathrm{Scr} / \kappa$ or 1 .
(2) Serum Cystatin C 2012 Equation (Age and Sex) [8]. Consider $133 \times \min (\text { Scys } / 0.8,1)^{-0.499} \times \max (\text { Scys } / 0.8,1)^{-1.328} \times$ $0.996^{\text {Age }}[\times 0.932$ if female $]$, where min indicates the minimum of $\mathrm{Scr} / \kappa$ or 1 and max indicates the maximum of Scys/ $\kappa$ or 1.

(3) Serum Creatinine in Combination with Cystatin C 2012 Equation (Age, Sex, and Race) [8]. Consider $135 \times \min (\mathrm{Scr} / \kappa, 1)^{\alpha} \times \max (\mathrm{Scr} / \kappa, 1)^{-0.601} \times$ $\min (\text { Scys } / 0.8,1)^{-0.375} \times \max (\text { Scys } / 0.8,1)^{-0.711} \times$ $0.995^{\text {Age }}[\times 0.969$ if female $][\times 1.08$ if black], where $\kappa$ is 0.7 for females and 0.9 for males, $\alpha$ is -0.248 for females and -0.207 for males, min indicates the minimum of $\mathrm{Scr} / \kappa$ or 1 , and max indicates the maximum of $\mathrm{Scr} / \kappa$ or 1.

(4) Average of the Serum Creatinine and the Serum Cystatin $C$ Equations [8]. GFR were also estimated with the other cystatin $\mathrm{C}$ equations in the supplementary material which were in the format of spline Log equations and additional adjusters of age, sex, race, history of diabetes, and weight, where min indicates minimum of standardized Scys $/ 0.8$ or 1 and max indicates maximum of standardized Scys/0.8 or 1 . The units of cystatin $\mathrm{C}$, age, and weight are in $\mathrm{mg} / \mathrm{L}$, years, and $\mathrm{kg}$, respectively [8].

(5) Spline Log Cystatin C Equation [8]. Consider $109 \times$ $\min (\text { Scys } / 0.8,1)^{-0.683} \times \max (\text { Scys } / 0.8,1)^{-1.367}$.

(6) Spline Log Cystatin C, Age, Sex, and Race Equation [8]. Consider $132 \times$ $\min (\text { Scys } / 0.8,1)^{-0.491} \times \max (\text { Scys } / 0.8,1)^{-1.329} \times$ $0.996^{\text {Age }}[\times 0.932$ if female $][\times 0.992$ if black $]$.

(7) Spline Log Cystatin C, Age, Sex, and Diabetes Equation [8]. Consider $126 \times$ $\min (\text { Scys } / 0.8,1)^{-0.362} \times \max (\text { Scys } / 0.8,1)^{-1.318} \times$ $0.997^{\text {Age }}[\times 0.934$ if female $][\times 1.068$ if diabetes $]$.

(8) Spline Log Cystatin C, Age, Sex, and Weight Equation [8]. Consider $132 \times \min (\text { Scys } / 0.8,1)^{-0.567} \times$ $\max (\text { Scys } / 0.8,1)^{-1.329} \times 0.996^{\text {Age }}[\times 0.949$ if female $] \times$ $1.002^{\text {Weight-80 }}$

First, we compared the characteristics of the study participants by categories of BMI using chi-square test or ANOVA as appropriate for the variable. Second, we estimated mean eGFR across BMI categories by all estimating equations. Tests for linear trend across BMI categories were performed using BMI categories as an ordinal variable in linear regression model. Third, we compared mean eGFR by diabetes and hypertension status for all equations and assessed the significance in difference by Student's $t$-test. Fourth, we estimated the mean difference in eGFR of the various equations compared to the CKD-EPI creatinine 2009 equation. Fifth, we calculated the proportion of participants falling into each eGFR category ( $>90,60-90$, $30-60,15-30$, and $<15 \mathrm{~mL} / \mathrm{min} / 1.73 \mathrm{~m}^{2}$ ) for all equations. Finally, using the CKD-EPI creatinine 2009 equation as the reference, we compared the concordance of CKD categories 
TABLE 1: Demographics and characteristics.

\begin{tabular}{|c|c|c|c|c|c|c|}
\hline \multirow{2}{*}{ Parameter* } & \multirow{2}{*}{$\begin{array}{c}(\text { mean } \pm \text { SD }) \\
\text { All patients } \\
(n=2877)\end{array}$} & \multicolumn{4}{|c|}{ Body mass index $\left(\mathrm{kg} / \mathrm{m}^{2}\right)$} & \multirow{2}{*}{$P$ value } \\
\hline & & $\begin{array}{c}<20 \\
(n=175)\end{array}$ & $\begin{array}{c}20-25 \\
(n=1071)\end{array}$ & $\begin{array}{c}25-30 \\
(n=1138)\end{array}$ & $\begin{array}{c}\geq 30 \\
(n=493)\end{array}$ & \\
\hline Age (years) & $57.3 \pm 9.7$ & 60.3 & 57.9 & 56.6 & 56.4 & $<0.001$ \\
\hline Male $(n, \%)$ & $1501,52.2$ & 57.7 & 59.9 & 52.5 & 32.9 & $<0.001$ \\
\hline Height $(\mathrm{cm})$ & $162 \pm 9$ & 163 & 164 & 162 & 160 & $<0.001$ \\
\hline Weight $(\mathrm{kg})$ & $69.2 \pm 13.6$ & 48.9 & 61.5 & 72.1 & 86.2 & $<0.001$ \\
\hline Body mass index $\left(\mathrm{kg} / \mathrm{m}^{2}\right)$ & $26.2 \pm 4.7$ & 18.4 & 22.9 & 27.2 & 33.7 & - \\
\hline Serum creatinine $(\mathrm{mg} / \mathrm{dL})$ & $0.87 \pm 0.29$ & 0.86 & 0.88 & 0.87 & 0.81 & $<0.001$ \\
\hline Serum cystatin C (mg/L) & $0.98 \pm 0.27$ & 0.98 & 0.97 & 0.97 & 1.03 & $<0.001$ \\
\hline Urine albumin to creatinine ratio $(\mathrm{mg} / \mathrm{g})$ & $41 \pm 139$ & 34 & 45 & 39 & 42 & 0.6 \\
\hline Systolic blood pressure (mm Hg) & $135 \pm 19.8$ & 132 & 134 & 136 & 137 & $<0.001$ \\
\hline Diastolic blood pressure $(\mathrm{mm} \mathrm{Hg})$ & $78 \pm 10.3$ & 75 & 78 & 79 & 77 & $<0.001$ \\
\hline Hypertension $(n, \%)$ & $1597,55.5$ & 45.1 & 50.6 & 57.4 & 65.5 & $<0.001$ \\
\hline Diabetes $(n, \%)$ & $948,33.0$ & 21.1 & 31.2 & 34.0 & 38.5 & $<0.001$ \\
\hline
\end{tabular}

${ }^{*}$ All parameters reported as mean $\pm \mathrm{SD}$, or frequency, \%. Conversion factor for unit: serum creatinine in $\mathrm{mg} / \mathrm{dL}$ to $\mu \mathrm{mol} / \mathrm{L}, \times 88.4$.

defined by all other equations and also compared the direction of eGFR change among the discordant categories. We did not consider the Modification of Diet in Renal Disease (MDRD) study equation because the study population is based on a general population and includes both CKD and healthy people without kidney disease. Moreover, estimates of GFR using the MDRD study equation can only be reported as $>60 \mathrm{~mL} / \mathrm{min} / 1.73 \mathrm{~m}^{2}$ for those with better function. It is an important function of this study to look at the variation of estimated GFR as a continuous variable throughout the range of estimation. Significance was taken at the 5\% level. All statistical analyses were performed using STATA version 12.0 (Texas, USA).

\section{Results}

$56.7 \%$ of the participants were either overweight (39.6\%) or obese $(17.1 \%)$ (Table 1). Obese participants were more likely to be younger, female, shorter, with lower levels of serum creatinine, with higher levels of serum cystatin C, with systolic blood pressure (SBP), and with higher prevalence of diabetes and hypertension. Those with BMI $<20 \mathrm{~kg} / \mathrm{m}^{2}$ $(175,6.1 \%)$ were more likely to be older, with lower levels of SBP, with diastolic blood pressure (DBP), and with lower prevalence of diabetes and hypertension.

The creatinine 2009 equation mean eGFR was similar to using spline Log cystatin C and both gave the highest mean eGFR of $88 \mathrm{~mL} / \mathrm{min} / 1.73 \mathrm{~m}^{2}$ with SD of 17 for eGFR creatinine and 22 for spline Log cystatin C. However, in the obese category $\left(\mathrm{BMI}>30 \mathrm{~kg} / \mathrm{m}^{2}\right)$, the spline Log cystatin C mean eGFR $\left(83 \pm 23 \mathrm{~mL} / \mathrm{min} / 1.73 \mathrm{~m}^{2}\right)$ was significantly lower than creatinine 2009 mean eGFR $\left(89 \pm 19 \mathrm{~mL} / \mathrm{min} / 1.73 \mathrm{~m}^{2}\right)(P<$ $0.001)$. The lowest mean eGFR $\left(81 \pm 21 \mathrm{~mL} / \mathrm{min} / 1.73 \mathrm{~m}^{2}\right)$ was obtained with the spline Log cystatin C-age, sex, and weight equation. Of all the BMI categories, mean eGFR was higher among subjects with BMI in the $20-25 \mathrm{~kg} / \mathrm{m}^{2}$ category and lower among obese subjects by all equations except creatinine $2009(P=0.2)$ and spline Log cystatin $C$-age, sex, and weight equation $(P=0.8)$. Compared to BMI in the 20 $25 \mathrm{~kg} / \mathrm{m}^{2}$ category, mean eGFR was also lower in the BMI < $20 \mathrm{~kg} / \mathrm{m}^{2}$ category. Generally, the inclusion of serum cystatin C resulted in eGFR that were lower than using creatinine 2009 except for the spline Log cystatin C equation.

Mean eGFR was lower in diabetic (except by spline Log cystatin $\mathrm{C}$ diabetes) and hypertensive subjects by all equations (Table 2(b)). The lowest mean eGFR was consistently obtained by the spline Log cystatin C-age, sex, and weight equation regardless of diabetes or hypertension status. The highest mean eGFR in nondiabetic patients was obtained with the creatinine 2009 equation $\left(90 \pm 16 \mathrm{~mL} / \mathrm{min} / 1.73 \mathrm{~m}^{2}\right)$, and the lowest mean eGFR $\left(82 \pm 19 \mathrm{~mL} / \mathrm{min} / 1.73 \mathrm{~m}^{2}\right)$ resulted from the spline Log cystatin C-age, sex, and weight equation $(P<0.001)$. The highest mean eGFR in diabetic patients $\left(86 \pm 25 \mathrm{~mL} / \mathrm{min} / 1.73 \mathrm{~m}^{2}\right)$ was obtained using the spline $\mathrm{Log}$ cystatin $\mathrm{C}$ equation versus the lowest mean eGFR of using the spline Log cystatin C-age, sex, and weight equation $\left(79 \pm 23 \mathrm{~mL} / \mathrm{min} / 1.73 \mathrm{~m}^{2}, P<0.001\right)$. Nonhypertensive participants had higher mean eGFR (ranging from $87 \pm 19$ to $93 \pm 21 \mathrm{~mL} / \mathrm{min} / 1.73 \mathrm{~m}^{2}$ ), whereas hypertensive patients had the lowest mean eGFR $\left(77 \pm 21\right.$ to $\left.84 \pm 23 \mathrm{~mL} / \mathrm{min} / 1.73 \mathrm{~m}^{2}\right)$ $(P<0.001$ by all equations).

The creatinine 2009 equation had the smallest proportion of participants (7.1\%) with eGFR $<60 \mathrm{~mL} / \mathrm{min} / 1.73 \mathrm{~m}^{2}$ and spline Log cystatin C-age, sex, and weight equation had the largest proportion (16.1\%) (Table 3). The equations incorporating serum creatinine for GFR estimation had the lowest proportion of participants with eGFR $<60 \mathrm{~mL} / \mathrm{min} / 1.73 \mathrm{~m}^{2}$ (creatinine $2009=7.1 \%$, creatinine-cystatin $\mathrm{C}=9.2 \%$, and average of creatinine and cystatin $\mathrm{C}=8.8 \%$ ). The cystatin C 2012 equation had more than double the proportion of patients $(14.6 \%)$ with eGFR $<60 \mathrm{~mL} / \mathrm{min} / 1.73 \mathrm{~m}^{2}$ compared to the creatinine 2009 equation (7\%). 
TABLE 2: (a) Distribution of mean estimated GFR by BMI categories. (b) Distribution of mean estimated GFR by disease subgroups.

(a)

\begin{tabular}{|c|c|c|c|c|c|c|}
\hline \multirow{3}{*}{ Equation } & \multicolumn{6}{|c|}{ Mean estimated GFR ${ }^{*}\left(\mathrm{~mL} / \mathrm{min} / 1.73 \mathrm{~m}^{2}\right)$} \\
\hline & \multirow{2}{*}{ All patients } & \multicolumn{4}{|c|}{ Body mass index $\left(\mathrm{kg} / \mathrm{m}^{2}\right)$} & \multirow{2}{*}{$P$ for trend } \\
\hline & & $<20$ & $20-25$ & $25-30$ & $>30$ & \\
\hline Creatinine 2009-age, sex, and race & $88 \pm 17$ & $87 \pm 18$ & $88 \pm 17$ & $88 \pm 17$ & $89 \pm 19$ & 0.2 \\
\hline Cystatin C 2012-age and sex & $83 \pm 21$ & $83 \pm 23$ & $85 \pm 21$ & $83 \pm 20$ & $78 \pm 21$ & $<0.001$ \\
\hline Creatinine-cystatin C 2012 (age, sex, and race) & $86 \pm 19$ & $85 \pm 20$ & $87 \pm 19$ & $86 \pm 18$ & $84 \pm 20$ & 0.02 \\
\hline Average of creatinine 2009 and cystatin C 2012 & $85 \pm 17$ & $85 \pm 19$ & $86 \pm 17$ & $85 \pm 17$ & $84 \pm 23$ & 0.03 \\
\hline Spline Log cystatin C & $88 \pm 22$ & $89 \pm 2$ & $90 \pm 22$ & $88 \pm 22$ & $83 \pm 23$ & $<0.001$ \\
\hline Spline Log cystatin C-age, sex, and race & $82 \pm 21$ & $82 \pm 23$ & $84 \pm 20$ & $83 \pm 20$ & $77 \pm 21$ & $<0.001$ \\
\hline Spline Log cystatin $\mathrm{C}$-age, sex, and diabetes & $85 \pm 20$ & $84 \pm 22$ & $86 \pm 20$ & $85 \pm 20$ & $80 \pm 21$ & $<0.001$ \\
\hline Spline Log cystatin C-age, sex, and weight & $81 \pm 21$ & $78 \pm 22$ & $82 \pm 20$ & $82 \pm 20$ & $79 \pm 22$ & 0.8 \\
\hline
\end{tabular}

${ }^{*}$ Estimated GFR reported as mean $\pm \mathrm{SD}$.

(b)

\begin{tabular}{|c|c|c|c|c|c|c|}
\hline \multirow{2}{*}{ Equation } & \multicolumn{6}{|c|}{ Mean estimated GFR ${ }^{*}\left(\mathrm{~mL} / \mathrm{min} / 1.73 \mathrm{~m}^{2}\right)$} \\
\hline & Nondiabetic & Diabetic & $P$ value & Nonhypertensive & Hypertensive & $P$ value \\
\hline Creatinine 2009 (age, sex, and race) & $90 \pm 16$ & $85 \pm 20$ & $<0.001$ & $92 \pm 15$ & $84 \pm 18$ & $<0.001$ \\
\hline Cystatin C 2012 (age and sex) & $84 \pm 19$ & $80 \pm 23$ & $<0.001$ & $88 \pm 19$ & $78 \pm 21$ & $<0.001$ \\
\hline Creatinine-cystatin C 2012 (age, sex, and race) & $87 \pm 17$ & $83 \pm 22$ & $<0.001$ & $91 \pm 16$ & $82 \pm 19$ & $<0.001$ \\
\hline Average of creatinine 2009 and cystatin C 2012 & $87 \pm 16$ & $82 \pm 20$ & $<0.001$ & $90 \pm 15$ & $81 \pm 18$ & $<0.001$ \\
\hline Spline Log cystatin C & $89 \pm 21$ & $86 \pm 25$ & 0.009 & $93 \pm 21$ & $84 \pm 23$ & $<0.001$ \\
\hline Spline Log cystatin C-age, sex, and race & $83 \pm 19$ & $80 \pm 23$ & $<0.001$ & $88 \pm 19$ & $78 \pm 21$ & $<0.001$ \\
\hline Spline Log cystatin C-age, sex, and diabetes & $84 \pm 19$ & $86 \pm 24$ & 0.01 & $89 \pm 18$ & $81 \pm 21$ & $<0.001$ \\
\hline Spline Log cystatin C-age, sex, and weight & $82 \pm 19$ & $79 \pm 23$ & $<0.001$ & $87 \pm 19$ & $77 \pm 21$ & $<0.001$ \\
\hline
\end{tabular}

${ }^{*}$ Estimated GFR reported as mean $\pm \mathrm{SD}$.

TABLE 3: Distribution of study population by mean estimated GFR categories.

\begin{tabular}{|c|c|c|c|c|c|c|}
\hline \multirow{3}{*}{ Equation } & \multicolumn{6}{|c|}{ Distribution $^{*} n, \%$} \\
\hline & \multicolumn{5}{|c|}{ Estimated GFR categories $\left(\mathrm{mL} / \mathrm{min} / 1.73 \mathrm{~m}^{2}\right)$} & \multirow{2}{*}{ eGFR $<60$} \\
\hline & $>90$ & $60-90$ & $30-60$ & $15-30$ & $\leq 15$ & \\
\hline Creatinine 2009 (age, sex, and race) & $1495,52.0$ & $1177,40.9$ & $191,6.6$ & $11,0.4$ & $3,0.1$ & $205,7.1$ \\
\hline Cystatin C 2012 (age and sex) & $1162,40.4$ & $1295,45.0$ & $395,13.7$ & $22,0.8$ & $3,0.1$ & $420,14.6$ \\
\hline Creatinine-cystatin C 2012 (age, sex, and race) & $1271,44.2$ & $1340,46.6$ & $248,8.6$ & $15,0.5$ & $3,0.1$ & $276,9.2$ \\
\hline Average of creatinine 2009 and cystatin C 2012 & $1253,43.6$ & $1371,47.7$ & $238,8.3$ & $12,0.4$ & $3,0.1$ & $253,8.8$ \\
\hline Spline Log cystatin C & $1384,48.1$ & $1184,41.2$ & $289,10.1$ & $18,0.6$ & $2,0.1$ & $309,10.8$ \\
\hline Spline Log cystatin $\mathrm{C}$-age, sex, and race & $1125,39.1$ & $1317,45.8$ & $410,14.3$ & $22,0.8$ & $3,0.1$ & $435,15.2$ \\
\hline Spline Log cystatin C-age, sex, and diabetes & $1249,43.4$ & $1271,44.2$ & $338,11.8$ & $17,0.6$ & $2,0.1$ & $357,12.5$ \\
\hline Spline Log cystatin C-age, sex, and weight & $1072,37.3$ & $1341,46.6$ & $438,15.2$ & $23,0.8$ & $3,0.1$ & $464,16.1$ \\
\hline
\end{tabular}

${ }^{*}$ Distribution reported as frequency count, $n$; percentage, $\%$.

When we compared the concordance of CKD stages classified by various cystatin $\mathrm{C}$ equations versus CKD-EPI creatinine 2009 equation (Table 4(a)), the concordance was the highest with the average of creatinine 2009 and cystatin C 2012 (78.1\%), followed by creatinine-cystatin C 2012age, sex, and race $(77.3 \%)$, and was the lowest with the spline Log cystatin C-age, sex, and weight (59.3\%). In general, the concordance was high at lower eGFR levels by all equations. Table 4(b) shows the direction of movement of eGFR categories comparing cystatin C equations to CKDEPI creatinine 2009 equation among those who were different. Movement to a higher category ranged from $5.9 \%$ with the average of creatinine 2009 and cystatin C 2012 to $14.8 \%$ with the spline Log cystatin C. Movement to a lower category ranged from 16\% (average of creatinine 2009 and cystatin C 2012) to $31.5 \%$ (spline Log cystatin C-age, sex, and weight). Under the $>90$ category, $13.2 \%$ to $22.8 \%$ were originally classified as $>90$ moved to a lower category by 


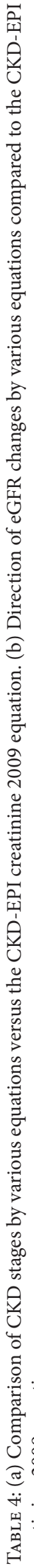

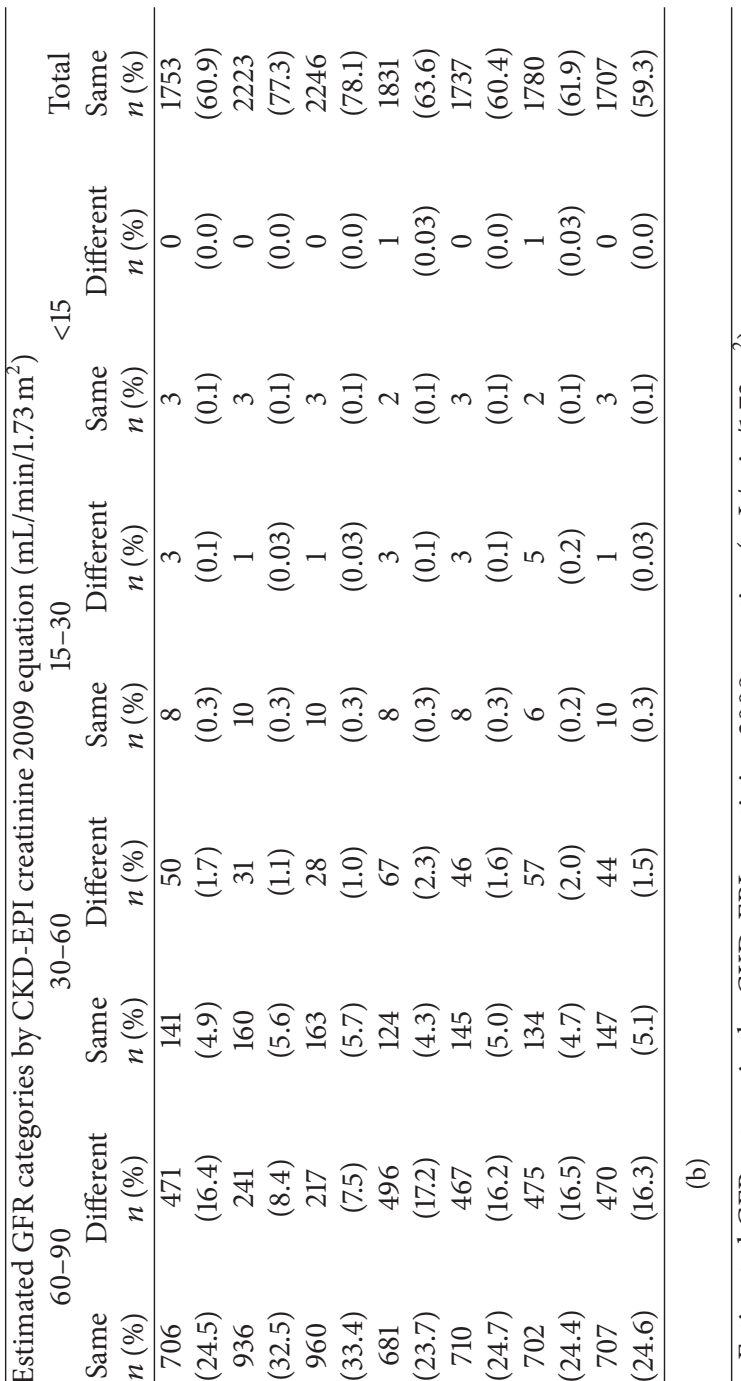

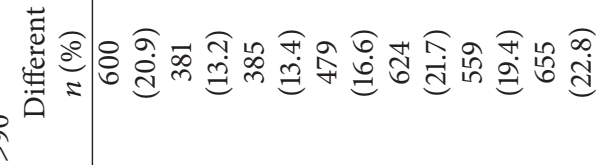

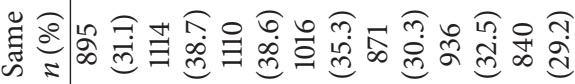

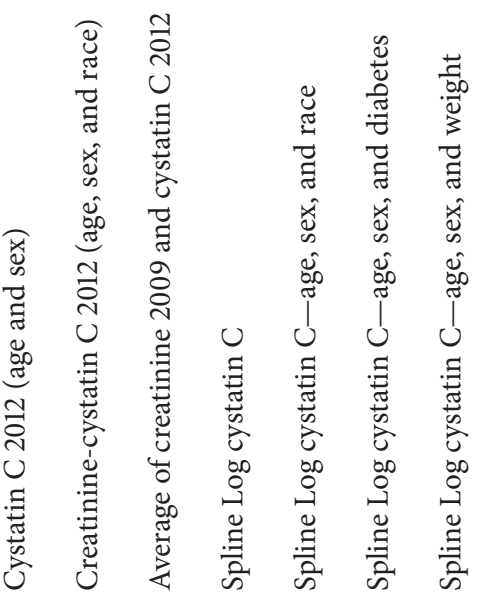

焉

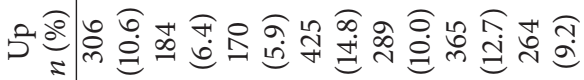

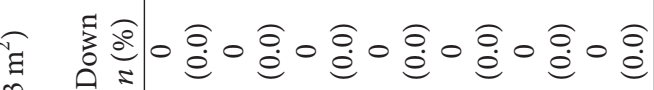

ㄴ.

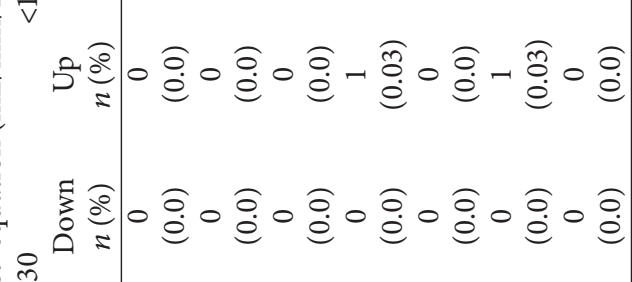

o

म

产

i

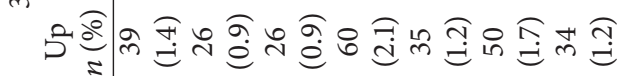
证

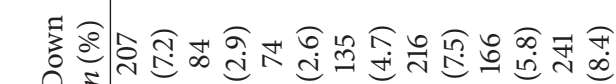
焉

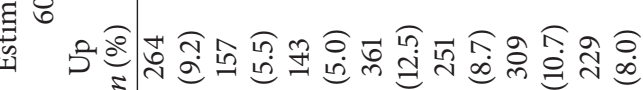

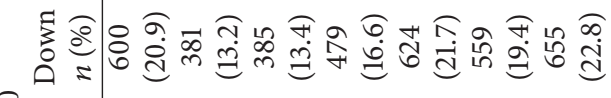
ฉ

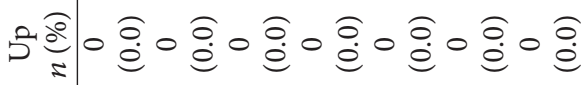

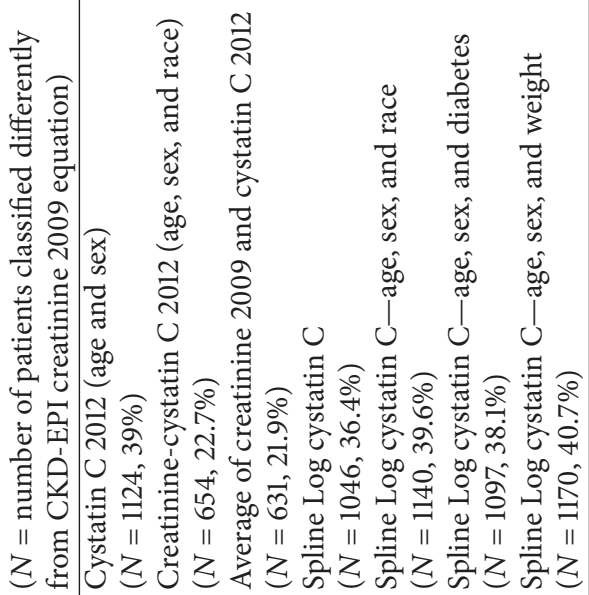




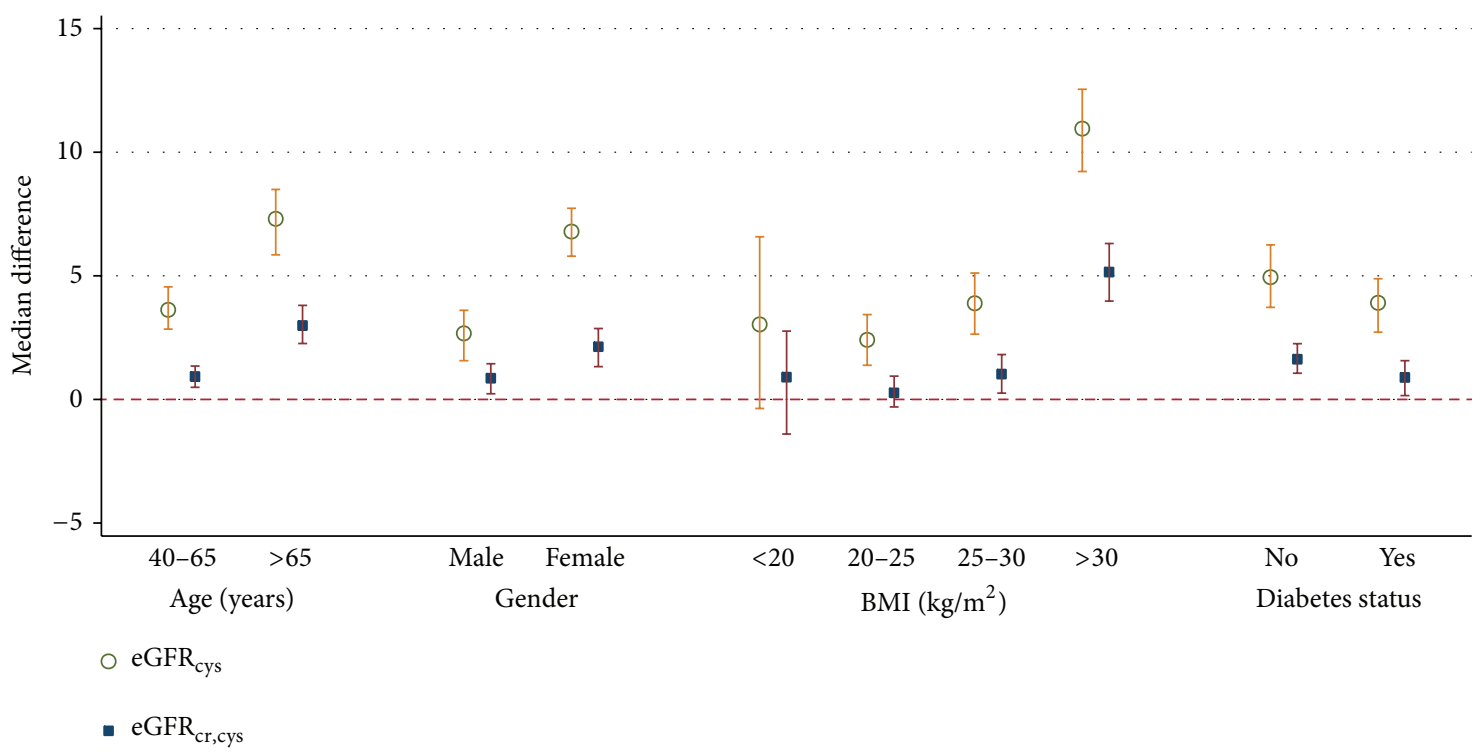

FIGURE 1: Performance of estimating equations by age, gender, BMI, and diabetes status. Referent equation: serum creatinine 2009 equation (age, sex, and race) [3].

the cystatin $\mathrm{C}$ equations. Under the $60-90$ category, $5 \%$ to $12.5 \%$ participants were originally classified to the $60-$ $90 \mathrm{~mL} / \mathrm{min} / 1.73 \mathrm{~m}^{2}$ category and $0.9 \%$ to $2.1 \%$ of those in the $30-60 \mathrm{~mL} / \mathrm{min} / 1.73 \mathrm{~m}^{2}$ category had eGFR changes that resulted in reclassification into a higher GFR category.

Compared to creatinine 2009 equation, the median difference in eGFR was larger when using the "cystatin C 2012 equation" than the "creatinine in combination with cystatin C 2012 equation" (Figure 1). The differences were the greatest in the elderly (age $>65$ years), women, obese (BMI $>30$ ), and nondiabetic participants.

\section{Discussion}

This is the largest study of a population-based cohort of Asian Indians comparing GFR estimation using a variety of equations incorporating serum creatinine alone, serum cystatin $\mathrm{C}$ alone, or in various combinations with other variables (age, sex, diabetes, and weight). In general, GFR estimation using serum cystatin $\mathrm{C}$ resulted in lower estimates (except using the spline Log cystatin C equation). Including cystatin $\mathrm{C}$ as a predictor resulted in lower estimated GFR in all participants except with the spline Log equation form (which did not consider the other predictors-age, sex, and race). The addition of age and sex as predictors into the spline Log equations lowered mean eGFR. "Diabetes" status increased mean eGFR, whereas "weight" as a predictor had a variable effect on mean eGFR.

Depending on the variables used, GFR estimations vary widely. Obese patients may have relatively reduced muscle mass resulting in lower serum creatinine levels and consequently a higher eGFR. However, we know that obese patients are also more likely to have diabetes and hypertension, conditions which are associated with kidney disease and dysfunction [10]. Incident hypertension and diabetes are also associated with elevated cystatin C levels $[10,11]$. Therefore, using serum cystatin $C$ in prediction equations may result in eGFR that could be more reflective of "true" GFR in obese patients. This highlights that different equation predictors (non-GFR determinants of marker concentrations) may substantively influence the resultant eGFR. Weight and obesity are non-GFR determinants and their influence on GFR marker levels may be due to ethnicity-related differences in body composition (percentage body fat and lean muscle mass) [12-16]. Serum cystatin C concentrations may be affected by body composition (fat mass) as the largest differences in GFR estimates occur in the obese $\left(\mathrm{BMI}>30 \mathrm{~kg} / \mathrm{m}^{2}\right)$, women, and the participants aged $>65$ years. Women in general have more body fat than men relative to muscle mass (influences serum creatinine concentrations). Similarly, older participants have reduced muscle mass and a relative higher proportion of body fat. Lower serum creatinine concentrations result in high estimated GFR; yet the higher serum cystatin $\mathrm{C}$ concentrations in women and older participants result in lower estimated GFR using the cystatin C-based equations, thereby accentuating the differences in estimates of GFR.

Consequent to the widely differing eGFR, the identification and staging of CKD are significantly affected. Clinical practice guidelines suggest that persistence of eGFR $<60 \mathrm{~mL} / \mathrm{min} / 1.73 \mathrm{~m}^{2}$ with a duration of more than 3 months might be considered CKD; the different cystatin C prediction equations resulted in different prevalence of CKD detected ( $8.8 \%$ to $16.1 \%)$, which varies with the prevalence detected by the creatinine only equation (7\%) [1]. Cystatin C $>1 \mathrm{mg} / \mathrm{L}$ is associated with an increased incidence of adverse outcomes despite having creatinine-based eGFR $>60 \mathrm{~mL} / \mathrm{min} / 1.73 \mathrm{~m}^{2}$ [17], and this may be related to incomplete assessment of risk due to an inaccurate eGFR [18]. Therefore, the addition of cystatin $\mathrm{C}$ as a predictor of GFR (which generally reduced mean 
eGFR in this study) may improve the identification of CKD. This has implications for the identification and treatment of CKD in the individual patient and also for the planning and allocation of healthcare resources for CKD management at the level of public health administration. Therefore, it is important that longitudinal studies are performed to assess the performance of these GFR estimation equations by linking clinical outcomes (end-stage renal disease and deaths), especially in ethnically diverse populations in Asia $[13,19-23]$.

The strengths of our study include a large populationbased single-ethnicity cohort with systematically collected demographic data, clinical history, serum, and urine samples. The study is limited by the absence of a reference standard GFR measurement and therefore cannot determine the "true" accuracy of these equations.

In summary we showed that using serum cystatin $\mathrm{C}$ as a predictor of GFR in estimation equations resulted in widely varying eGFR which significantly affected the identification and classification of chronic kidney disease. Further research linking these equations to longitudinal clinical outcomes in other Asian populations is required.

\section{Conflict of Interests}

The authors declare that they have no potential conflict of interests regarding the publication of the paper.

\section{Authors' Contribution}

Boon Wee Teo and Charumathi Sabanayagam conceived, supervised, and conducted the study. Tien Yin Wong recruited the participants. Jiemin Liao analyzed the data. Boon Wee Teo and Charumathi Sabanayagam interpreted the data. Sunil Sethi, Sharon Saw, Qi Chun Toh, and Boon Wee Teo supervised the laboratory measurements of specimens. Boon Wee Teo, Charumathi Sabanayagam, and Qi Chun Toh wrote the initial draft of the paper. All the authors reviewed and edited the paper.

\section{Acknowledgment}

This study was funded by the Ministry of Education Academic Research Fund Grant (T1-2012Feb-01) awarded to Professor Sunil Sethi by the Faculty Research Committee of the Yong Loo Lin School of Medicine, National University of Singapore.

\section{References}

[1] "K/DOQI clinical practice guidelines for chronic kidney disease: evaluation, classification, and stratification," American Journal of Kidney Diseases, vol. 39, supplement 1, no. 2, pp. S1S266, 2002.

[2] A. S. Levey, J. P. Bosch, J. B. Lewis, T. Greene, N. Rogers, and D. Roth, "A more accurate method to estimate glomerular filtration rate from serum creatinine: a new prediction equation," Annals of Internal Medicine, vol. 130, no. 6, pp. 461-470, 1999.
[3] A. S. Levey, L. A. Stevens, C. H. Schmid et al., "A new equation to estimate glomerular filtration rate," Annals of Internal Medicine, vol. 150, no. 9, pp. 604-612, 2009.

[4] A. D. Rule, K. R. Bailey, G. L. Schwartz, S. Khosla, J. C. Lieske, and L. J. Melton III, "For estimating creatinine clearance measuring muscle mass gives better results than those based on demographics," Kidney International, vol. 75, no. 10, pp. 10711078, 2009.

[5] Y.-C. Ma, L. Zuo, J.-H. Chen et al., "Improved GFR estimation by combined creatinine and cystatin C measurements," Kidney International, vol. 72, no. 12, pp. 1535-1542, 2007.

[6] L. A. Stevens, J. Coresh, C. H. Schmid et al., "Estimating GFR using serum cystatin $\mathrm{C}$ alone and in combination with serum creatinine: a pooled analysis of 3,418 individuals with CKD," American Journal of Kidney Diseases, vol. 51, no. 3, pp. 395-406, 2008.

[7] B. W. Teo, H. Xu, D. Wang et al., "Estimating glomerular filtration rates by use of both cystatin $\mathrm{C}$ and standardized serum creatinine avoids ethnicity coefficients in asian patients with chronic kidney disease," Clinical Chemistry, vol. 58, no. 2, pp. 450-457, 2012.

[8] L. A. Inker, C. H. Schmid, H. Tighiouart et al., "Estimating glomerular filtration rate from serum creatinine and cystatin C," New England Journal of Medicine, vol. 367, no. 1, pp. 20-29, 2012.

[9] R. Lavanya, V. S. E. Jeganathan, Y. Zheng et al., "Methodology of the Singapore Indian Chinese Cohort (SICC) eye study: quantifying ethnic variations in the epidemiology of eye diseases in Asians," Ophthalmic Epidemiology, vol. 16, no. 6, pp. 325-336, 2009.

[10] B. Kestenbaum, K. D. Rudser, I. H. De Boer et al., "Differences in kidney function and incident hypertension: the multi-ethnic study of atherosclerosis," Annals of Internal Medicine, vol. 148, no. 7, pp. 501-508, 2008.

[11] R. P. Donahue, S. Stranges, K. Rejman, L. B. Rafalson, J. Dmochowski, and M. Trevisan, "Elevated cystatin C concentration and progression to pre-diabetes: the Western New York Study," Diabetes Care, vol. 30, no. 7, pp. 1724-1729, 2007.

[12] P. Deurenberg, M. Deurenberg-Yap, and S. Guricci, "Asians are different from Caucasians and from each other in their body mass index/body fat per cent relationship," Obesity Reviews, vol. 3, no. 3, pp. 141-146, 2002.

[13] M. G. Shlipak, C. L. W. Fyr, G. M. Chertow et al., "Cystatin $\mathrm{C}$ and mortality risk in the elderly: the health, aging, and body composition study," Journal of the American Society of Nephrology, vol. 17, no. 1, pp. 254-261, 2006.

[14] P. Muntner, J. Winston, J. Uribarri, D. Mann, and C. S. Fox, "Overweight, obesity, and elevated serum cystatin C levels in adults in the United States," American Journal of Medicine, vol. 121, no. 4, pp. 341-348, 2008.

[15] R. Retnakaran, P. W. Connelly, S. B. Harris, B. Zinman, and A. J. G. Hanley, "Cystatin C is associated with cardiovascular risk factors and metabolic syndrome in Aboriginal youth," Pediatric Nephrology, vol. 22, no. 7, pp. 1007-1013, 2007.

[16] J. A. Young, S.-J. Hwang, and C. S. Fox, "Association of visceral and subcutaneous adiposity with kidney function," Clinical Journal of the American Society of Nephrology, vol. 3, no. 6, pp. 1786-1791, 2008.

[17] M. G. Shlipak, R. Katz, M. J. Sarnak et al., "Cystatin C and prognosis for cardiovascular and kidney outcomes in elderly persons without chronic kidney disease," Annals of Internal Medicine, vol. 145, no. 4, pp. 237-246, 2006. 
[18] V. Menon, M. G. Shlipak, X. Wang et al., "Cystatin C as a risk factor for outcomes in chronic kidney disease," Annals of Internal Medicine, vol. 147, no. 1, pp. 19-27, 2007.

[19] M. Madero and M. J. Sarnak, "Association of cystatin C with adverse outcomes," Current Opinion in Nephrology and Hypertension, vol. 18, no. 3, pp. 258-263, 2009.

[20] B. A. Perkins, R. G. Nelson, B. E. P. Ostrander et al., "Detection of renal function decline in patients with diabetes and normal or elevated GFR by serial measurements of serum cystatin C concentration: results of a 4-year follow-up study," Journal of the American Society of Nephrology, vol. 16, no. 5, pp. 1404-1412, 2005.

[21] D. E. Rifkin, M. G. Shlipak, R. Katz et al., "Rapid kidney function decline and mortality risk in older adults," Archives of Internal Medicine, vol. 168, no. 20, pp. 2212-2218, 2008.

[22] A. Köttgen, E. Selvin, L. A. Stevens, A. S. Levey, F. Van Lente, and J. Coresh, "Serum Cystatin C in the United States. The Third National Health and Nutrition Examination Survey (NHANES III)," American Journal of Kidney Diseases, vol. 51, no. 3, pp. 385394, 2008.

[23] M. G. Shlipak, K. Matsushita, J. A. Ärnlöv et al., "Cystatin C versus creatinine in determining risk based on kidney function," New England Journal of Medicine, vol. 369, no. 10, pp. 932-943, 2013. 


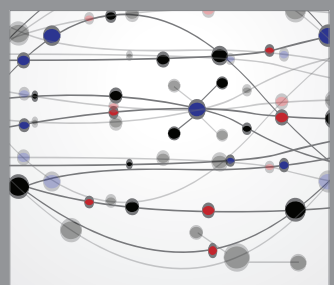

The Scientific World Journal
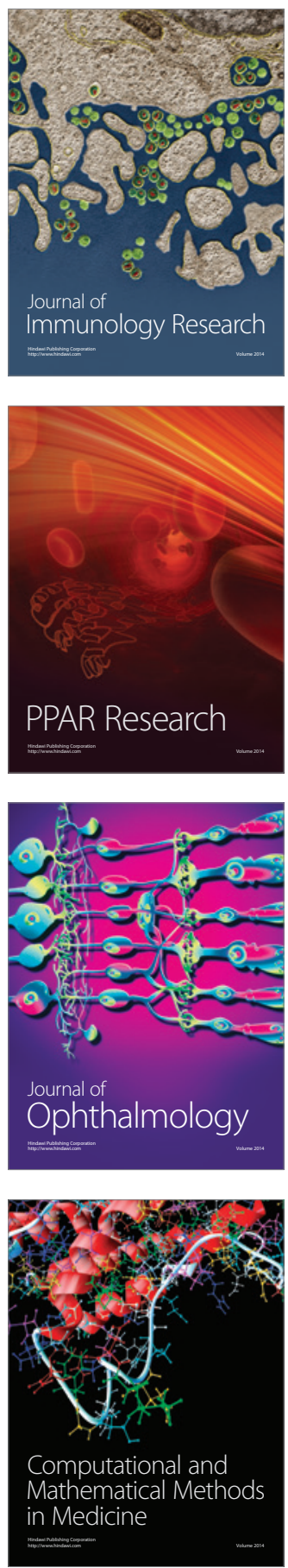

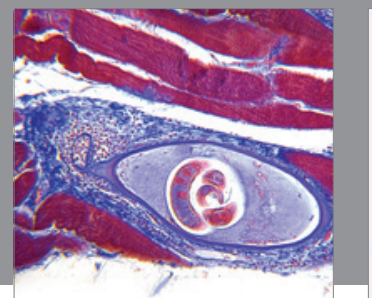

Gastroenterology

Research and Practice
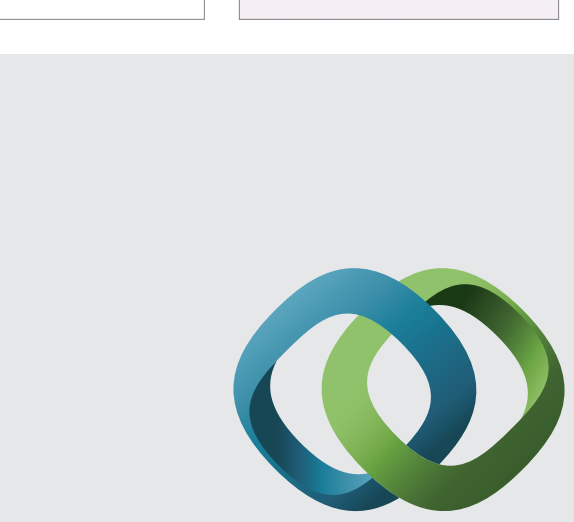

\section{Hindawi}

Submit your manuscripts at

http://www.hindawi.com
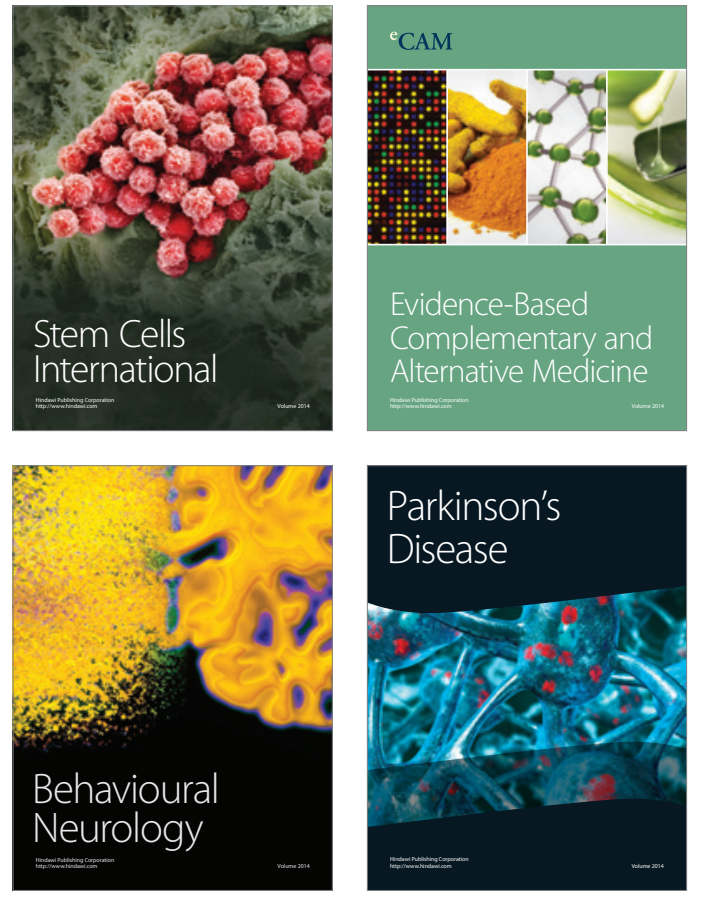
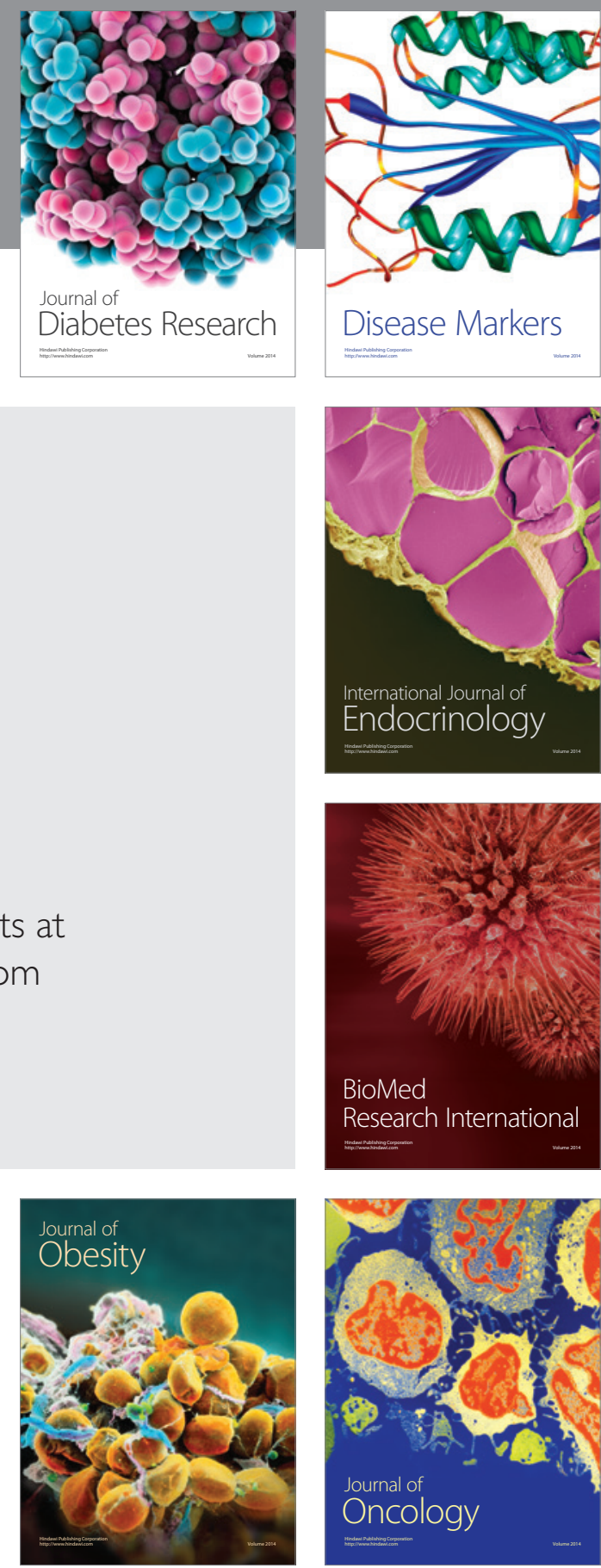

Disease Markers
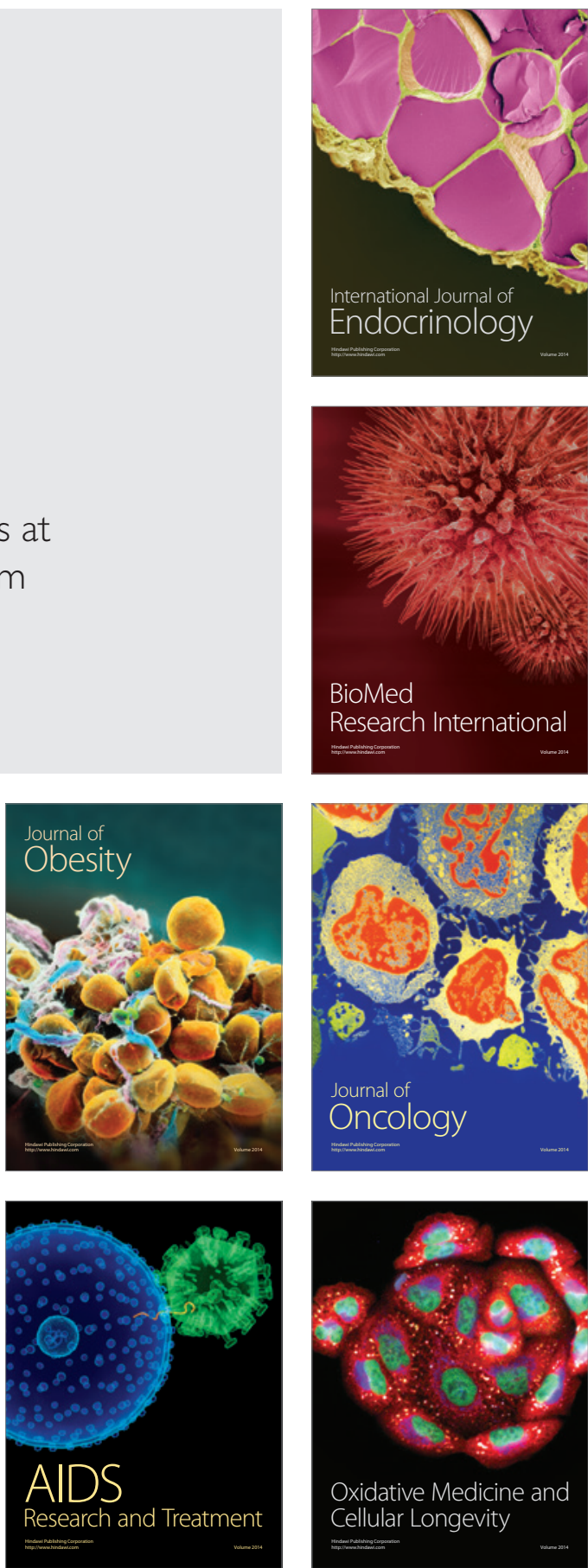